Accurate Prediction of Emission Energies with TD-DFT Methods for Platinum and Iridium OLED Materials

Glenn R. Morello

Centre for Theoretical and Computational Chemistry and Department of Chemistry, UiT - The Arctic University of Norway, N-9037 Tromsø Norway

Email: glenn.r.morello@uit.no

Phone: +4793632780

\begin{abstract}
Accurate prediction of triplet excitation energies for transition metal complexes has proven to be a difficult task when confronted with a variety of metal centers and ligand types. Specifically, phosphorescent transition metal light emitters, typically based on iridium or platinum, often give calculated results of varying accuracy when compared to experimentally determined T1 emission values. Developing a computational protocol for reliably calculating OLED emission energies will allow for the prediction of a complexes color prior to synthesis, saving time and resources in the laboratory. A comprehensive investigation into the dependence of the DFT functional, basis set, and solvent model is presented here, with the aim of identifying an accurate method while remaining computationally cost-effective. A protocol that uses TD-DFT excitation energies on ground-state geometries was used to predict triplet emission values of 34 experimentally characterized complexes, using a combination of gas phase B3LYP/LANL2dz for optimization and B3LYP/CEP-31G/PCM(THF) for excitation energies. Results show excellent correlation with experimental emission values of iridium and platinum complexes for a wide range of emission energies. The set of complexes tested includes neutral and charged complexes as well as a variety of different ligand types.
\end{abstract}




\title{
Accurate Prediction of Emission Energies with TD-DFT Methods for Platinum and Iridium OLED Materials
}

\author{
Glenn R. Morello
}

\section{Introduction}

Since the introduction of the first phosphorescent materials and devices proven to work as triplet emitters[1-3], Fig. 1, numerous groups have synthesized novel TM complexes for use in organic light emitting diode (OLED) devices. Iridium(III) and platinum(II) complexes make up the majority of emissive complexes studied due to their thermal stability, emission energies that can be tuned by modification of the ligands, and good quantum efficiencies in devices. For example, Yasukawa et al. have patented novel iridium- and platinum-based complexes consisting of trivalent linking groups for light emission of various wavelengths.[4] Kimyonok et al. showed that a series of synthesized iridium-copolymer dopant/host devices can be tuned to emit from $474 \mathrm{~nm}$ to $600 \mathrm{~nm}$ and exhibit quantum efficiencies similar to the well known Ir(ppy) ${ }_{3}$ dopant.[5,3] Rausch et al. have improved the rigidity in platinum(II) complexes by using a tridentate ligand, resulting in much higher photoluminescent quantum efficiencies compared to a bidentate analogue.[6] Solomatina et al. have explored Pt(II) complexes with N-heterocyclic carbene (NHC) ligands that emit in the blue/green region of the spectrum.[7] Tuning of the quantum efficiencies can be achieved by augmenting the ligand sphere around the metal.[7]

Computational methods are often employed to predict a complex's lowest triplet emission energy (T1), determine the ground and excited state geometries, or visualize the location of electron density contributing to the emission. As with most applications of computational methods, knowing a priori what method provides the most accurate results is often a subject of debate. Shang et al. reported TD-DFT calculated emission values for an iridium complex that differ by $13 \mathrm{~nm}$ and $69 \mathrm{~nm}$ (M062X and B3LYP, respectively) from experimental values.[8] Their work used optimized triplet geometries as the input for the TD-DFT calculation, requiring a larger computational effort. Recent work by $\mathrm{Xu}$ et al., used TD-DFT methods towards prediction of $\mathrm{T} 1$ emission for a number of iridium complexes.[9] This approach required triplet state geometry optimizations with numerous functionals, using an average of all the results multiplied by 1.2 as the final predicted value T1 value. The use of gas phase calculations to compare to frozen solutions $(77 \mathrm{~K})$ may miss important interactions between host (solvent) and dopant (TM complex).[10-12] These interactions will become even more important when charged complexes are being used as dopants. Previous unpublished results from our lab determined that while gas phase time-dependent density functional theory calculations (TD-DFT, vertical excitations) work well for predicting T1 energies of iridium(III) complexes, the same method often leads to large errors in $\mathrm{T} 1$ when $\mathrm{Pt}(\mathrm{II})$ complexes are studied. Niehaus et al. have recently shown good agreement between calculated emission energies, using TD-DFT vertical excitations, and experimental emission values for iridium and platinum complexes. Specifically, calculated mean average percent deviations (MAPD) using B3LYP (1.8\%) or the modified LC-PBE $(4.6 \%)$ functionals, with a solvent model, within the TD-DFT framework provided a vast improvement over the original PBE (14.3\%) functional.[13]

An efficient computational method must be able to quickly, as well as accurately, predict ground state geometries and T1 emission energies of complexes with varying ligand sets. Methods such as $\triangle \mathrm{SCF}$, which requires triplet optimization, time consuming configuration interaction (CI) calculations, and the use of very large basis sets should be avoided if possible. Additionally, methods like Herein we report the identification of linear-response TD-DFT based method for the accurate prediction of emission energies for phosphorescent platinum(II) and iridium(III) complexes. Accuracy was maintained across the visible spectrum from deep blue to red emission. Application of this method towards different metals and different ligand sets shows its versatility and is expected to be accurate in its prediction of emission energies of novel complexes prior to synthesis.

\section{Computational Methods}

All calculations were performed with the Gaussian 09 package.[14] Optimization of ground state singlet geometries were carried out with the density functional theory[15,16] (DFT) framework using various functional/basis set/solvation combinations. Basis sets ranged from full relativistic effective core potentials (RECPs) to split-basis methods (metal treated with RECPs and main group atoms with an all-electron basis).

Optimized ground state geometries were treated with time-dependent DFT (TD-DFT)[17-19] calculations to obtain vertical excitation energies for the first 3 singlet and 3 triplet states. Comparison of computed vertical excitations to experimental emission energies of OLED materials is justified since OLED transient lifetimes are typically on the order of a few microseconds[20], thus emission can be considered as instantaneous (before nuclei can reorder) making the vertical electronic transition a good approximation of the emission energy. Additionally, the rigid structure of the complexes through the use of bidentate ligands, and their fairly locked geometry in the organic host material dramatically reduces the vibrational relaxation and reorganization energies. This can be seen by an OLEDs relatively small Stokes shift.[21]

The obtained results are categorized into three major sets:

(1) variation of the density functional

(2) variation of the basis set

(3) variation of the solvation model.

The first set of calculations (1) explored the effect of varying the density functional. The functionals B3LYP[22], PBE0[23,24], M06, M06-L, M06-HF[25-28] and BP86[29,30] were employed to determine how the amount and form of exchange-correlation influences the calculated excitation values. Additionally, the CAM-B3LYP[31] and M11[32] functionals were used to test if varying the exchange (at short range 
and long range) impacts the calculated T1. The $\omega \mathrm{B} 97 \mathrm{X}-\mathrm{D}[33]$ functional was also tested to see the effect dispersion has on the calculations. The functionals were used for both the geometry optimization and the TD-DFT calculations. Functionals that gave the best agreement with experimental data were then passed on to the next set of calculations.

The second set of calculations (2) examined the calculated excitation energies dependence on the basis set. Relativistic effective core potential (RECP) basis sets are used to avoid time consuming all electron basis sets for transition metal atoms, as well as to include relativistic effects of heavy atoms. The basis sets selected comprise of the double and triple zeta basis sets developed by Stephens et al[34], CEP-31G and CEP-121G, respectively, and the Los Alamos double zeta LANL2dz[35-38] basis set. Additional calculations were performed using split-basis sets that employ a RECP on metal atoms and an all-electron basis set on all non-metal atoms. The 6-31 $\mathrm{g}(\mathrm{d})[39,40]$ and 6-311g(d,p)[41,42] basis sets were both tested to treat main group atoms. Additional $d$-orbital polarization functions were added to phosphorus and chlorine atoms when present.

Lastly, set (3) consists of various solvation models to further improve the accuracy of calculated results. While the CPCM was used in sets (1) and (2) alongside gas phase calculations to determine the best functional/basis set method, IEFPCM[43,44], and SMD[45] solvation models were later evaluated on the best method to ensure the best solvation model is used. All but two complexes were experimentally tested in tetrahydrofuran (THF) or 2-methyl-THF at $77 \mathrm{~K}$, while $298 \mathrm{~K}$ data was obtained in dichloromethane $\left(\mathrm{CH}_{2} \mathrm{Cl}_{2}\right)$. Comparison of the dielectric constants for THF (7.42) and $\mathrm{CH}_{2} \mathrm{Cl}_{2}$ (8.93) suggest that calculations will not deviate much between the two, therefore THF was selected as the solvent for all calculations that employ a solvation model.

The general nomenclature used in this paper for the combinations of functionals and basis sets used for DFT optimization and TD-DFT excitation calculations is as follows; $\mathrm{F} / \mathrm{O} / \mathrm{P}$, where $\mathrm{F}$ is the functional of choice, $\mathrm{O}$ is the basis set used for geometry optimization, and $\mathrm{P}$ is the phase (gas or THF) used for the excitation energy calculation. For example; a calculation denoted B3LYP/LANL2dz/THF used the B3LYP functional and the LANL2dz basis set for both geometry optimization and excited state calculation, with THF used only in the TD-DFT calculation. If the basis set and/or functional used in the excitation energy calculation was different than the basis set used for optimization, it is denoted explicitly, for example: B3LYP/LANL2dz/CEP-31G_THF.

\section{Results and Discussion}

A total of $34 \mathrm{TM}$ complexes were screened through various functional/basis set/solvation methodologies, Table 1 and Fig. 2. This set comprised of OLEDs that span a variety of ligand types and emission wavelengths, which is critical due to the nature of the electromagnetic spectrum. Specifically, small differences in the blue region amount to a larger difference in energy compared to small differences in the red region of the visible spectrum. Therefore, a best method must be able to accurately differentiate small changes in emission energies for complexes with similar or different ligands.

Table 1. Experimental T1 emission values of the transition metal OLED complexes investigated in this work.

\begin{tabular}{cccc} 
& \multicolumn{3}{c}{ Experimental } \\
\cline { 2 - 4 } Complex & $\lambda_{\text {em }, \mathbf{n m}}$ & $\boldsymbol{\lambda}_{\text {em, }}$ nm & Reference \\
$\mathbf{( 7 7}$ K) & $(\mathbf{2 9 8}$ K) & $\#$ \\
\hline Ir1 & 491 & 508 & {$[46]$} \\
Ir2 & - & 475 & {$[47]$} \\
Ir3 & - & 480 & {$[1]$} \\
Ir4 & - & 456 & {$[48]$} \\
Ir5 & - & 455 & {$[48]$} \\
Ir6 & - & 458 & {$[48]$} \\
Ir7 & - & 431 & {$[48]$} \\
Ir8 & - & 438 & {$[49]$} \\
Ir9 & 443 & 466 & {$[8]$} \\
Ir10 & 463 & 555 & {$[50]$} \\
Ir11 & 464 & 555 & {$[50]$} \\
Ir12 & 456 & 554 & {$[50]$} \\
Ir13 & 458 & 474 & {$[51]$} \\
Ir14 & 465 & 480 & {$[51]$} \\
Pt1 & 480 & 486 & {$[52]$} \\
Pt2 & 477 & - & {$[52]$} \\
Pt3 & 480 & - & {$[52]$} \\
Pt4 & 480 & 485 & {$[52]$} \\
Pt5 & 468 & 476 & {$[52]$} \\
Pt6 & 487 & - & {$[52]$} \\
Pt7 & 476 & 484 & {$[52]$} \\
Pt8 & 458 & 466 & {$[52]$} \\
Pt9 & 438 & 456 & {$[52]$} \\
Pt10 & 440 & 447 & {$[52]$} \\
Pt11 & 555 & - & {$[52]$} \\
Pt12 & 488 & 495 & {$[53]$} \\
Pt13 & 489 & 495 & {$[53]$} \\
Pt14 & 473 & 480 & {$[53]$} \\
Pt15 & 493 & 506 & {$[54]$} \\
Pt16 & 432 & 467 & {$[54]$} \\
\hline
\end{tabular}




\begin{tabular}{llll}
\hline Pt17 & 570 & 595 & {$[54]$} \\
Pt18 & 525 & 569 & {$[54]$} \\
Pt19 & 440 & 478 & {$[55]$} \\
Pt20 & 515 & 527 & {$[56]$} \\
\hline
\end{tabular}

Functional Dependence. Work by $\mathrm{Xu}$ and coworkers has provided insight into the functional dependence of calculated T1 emissions.[9] They have previously shown that functionals containing a certain amount of exact Hartree-Fock exchange (HF) perform better than functionals without this exchange. Therefore a critical first step was to calibrate our results against functionals selected by $\mathrm{Xu}$, include a larger set of the Minnesota functionals, and explore functionals with range-separated exchange formalism and dispersion corrections. Initial calculations employed the CEP-31G basis set in gas and solvated phases. The CPCM solvation model was used using tetrahydrofuran, THF, as the solvent (selection of solvent is discussed in detail below). The calculated emission energies were compared to both $298 \mathrm{~K}$ and frozen $77 \mathrm{~K}$ OLED experimental emission data.

Table 2. Comparison of the mean average percent deviations (MAPD) for calculated T1 vertical emission energies for iridium(III) OLED complexes against the experimentally reported values (Table 1) in gas phase and THF (CPCM solvation model).

\begin{tabular}{|c|c|c|c|c|c|}
\hline \multirow[b]{2}{*}{ Functional $^{a}$} & \multirow[b]{2}{*}{$\begin{array}{c}\% \text { HF } \\
\text { Exchang } \\
\text { e }\end{array}$} & \multicolumn{4}{|c|}{ Iridium(III) Complexes } \\
\hline & & $\begin{array}{c}\text { MAPD } \\
\text { Gas (298 } \\
\text { K) }\end{array}$ & $\begin{array}{c}\text { MAPD }^{b} \\
\text { Gas (77 } \\
\text { K) }\end{array}$ & $\begin{array}{c}\text { MAPD }^{c} \\
\text { THF (298 } \\
\text { K) }\end{array}$ & $\begin{array}{c}\text { MAPD }^{b} \\
\text { THF } \\
(77 K)\end{array}$ \\
\hline B3LYP & 20 & 2.8 & 7.5 & 4.4 & 1.7 \\
\hline CAM-B3LYP & $19 / 65^{d}$ & 5.2 & 3.3 & 5.2 & 3.2 \\
\hline M06 & 27 & 3.8 & 6.2 & 7.2 & 3.1 \\
\hline M06-L & 0 & 10.7 & 25.5 & 5.1 & 16.4 \\
\hline M06-HF & 100 & 31.8 & 29.7 & 33.4 & 31.5 \\
\hline M06-2X & 54 & 20.6 & 16.7 & 21.2 & 16.5 \\
\hline M11 & $42.8 / 100^{d}$ & 16.6 & 13.7 & 17.7 & 15.0 \\
\hline PBEO & 25 & 21.7 & 37.1 & 13.1 & 25.9 \\
\hline BP86 & 0 & 21.6 & 37.0 & 13.0 & 25.9 \\
\hline$\omega B 97 X-D$ & $22 / 100$ & 6.1 & 10.0 & 6.0 & 9.8 \\
\hline
\end{tabular}

${ }^{a}$ Only the functional varied in calculations. CEP-31G basis set for all atoms.

${ }^{b} 7$ of the 14 iridium complexes had $77 \mathrm{~K}$ data.

c 14 of the 14 iridium complexes had $298 \mathrm{~K}$ data.

${ }^{d}$ range separated functionals listed with short/long percentages of HF exchange.

Results in Table 2 show that the amount of HF exchange in the functionals influences the calculated vertical excitation energies, based on optimized singlet geometries, quite differently than $\mathrm{Xu}$ reports for triplet geometry TD-DFT calculations.[9] Specifically, Table 2 shows there is less dependence on the amount of HF exchange when calculating the TD-DFT emission of iridium complexes from the optimized ground state singlet geometry. The functionals with the best correlation to experimental data are B3LYP and M06, consisting of $20 \%$ and $27 \% \mathrm{HF}$, respectively. It can be extracted from Table 2 that the best correlation is found between calculated THF values and $77 \mathrm{~K}$ experimental values, and will therefore be the focus of this discussion. At the individual level, only 3 complexes have a calculated $\Delta_{\mathrm{nm}}$ ( $\mathrm{T} 1_{\text {CalcTHF- }}$ T1 $\left.1_{\text {Exp } 77 \mathrm{~K}}\right)$ greater than $10 \mathrm{~nm}$ in the B3LYP/CEP-31G/THF $(77 \mathrm{~K})$ data set; $\operatorname{Ir9}(11 \mathrm{~nm}), \operatorname{Ir11}(15 \mathrm{~nm})$, and $\operatorname{Ir12}(14 \mathrm{~nm})$. These values compute to small mean average percent deviations (MAPD) of $2.5 \%, 3.2 \%$, and $3.1 \%$, respectively.

Results for the platinum complexes exhibit the same trend as iridium, with B3LYP and M06 proving to be the best functionals with the CEP-31G basis set, Table 3 . Here M06 shows a slightly better performance for platinum complexes having a calculated MAPD of $2.0 \%$ compared to $3.7 \%$ with B3LYP in the $77 \mathrm{~K}$ data set.

Table 3. Comparison of the calculated mean average percent deviations (MAPD) for platinum(II) OLED complexes against the experimentally reported values (Table 1) in gas phase and THF (CPCM solvation model).

\begin{tabular}{|c|c|c|c|c|c|}
\hline \multirow[b]{2}{*}{ Functional $^{a}$} & \multirow[b]{2}{*}{$\begin{array}{c}\% \text { HF } \\
\text { Exchange }\end{array}$} & \multicolumn{4}{|c|}{ Platinum(II) Complexes } \\
\hline & & $\begin{array}{c}\text { MAPD } \\
\text { Gas (298 } \\
\text { K) } \\
\end{array}$ & $\begin{array}{c}\text { MAPD }^{b} \\
\text { Gas (77 } \\
\text { K) }\end{array}$ & $\begin{array}{c}\text { MAPD }^{c} \\
\text { THF (298 } \\
\text { K) }\end{array}$ & $\begin{array}{c}\text { MAPD }^{b} \\
\text { THF } \\
(77 K)\end{array}$ \\
\hline B3LYP & 20 & 4.7 & 7.2 & 2.3 & 3.7 \\
\hline CAM-B3LYP & $19 / 65$ & 4.3 & 5.9 & 3.3 & 4.9 \\
\hline M06 & 27 & 2.2 & 2.7 & 4.6 & 2.0 \\
\hline M06-L & 0 & 15.7 & 17.5 & 8.4 & 10.9 \\
\hline M06-HF & 100 & 20.6 & 17.7 & 20.2 & 17.2 \\
\hline M06-2X & 54 & 13.6 & 11.1 & 15.2 & 12.7 \\
\hline M11 & $42.8 / 100$ & 10.1 & 7.9 & 11.2 & 9.0 \\
\hline PBEO & 25 & 22.6 & 29.5 & 18.2 & 20.3 \\
\hline BP86 & 0 & 27.3 & 28.6 & 17.4 & 21.3 \\
\hline$\omega B 97 X-D$ & $22 / 100$ & 9.1 & 13.1 & 9.1 & 13.2 \\
\hline
\end{tabular}

${ }^{a}$ Only the functional varied in calculations. CEP-31G basis set for all atoms.

${ }^{b} 20$ of the 20 platinum complexes had $77 \mathrm{~K}$ data. 
${ }^{c} 16$ of the 20 platinum complexes had $298 \mathrm{~K}$ data.

${ }^{d}$ range separated functionals listed with short/long percentages of HF exchange.

The platinum group consists of 19 complexes having a $\Delta_{\mathrm{nm}}$ greater than $10 \mathrm{~nm}$ with the B3LYP/CEP31G/THF method. Moreover, 4 of these (Pt4, Pt8, Pt9, Pt21) have calculated values red-shifted by more than $20 \mathrm{~nm}$, while 2 complexes (Pt18, Pt29) are red-shifted by $30 \mathrm{~nm}$ or more. Comparison of Table 2 and Table 3 clearly shows that selection of the functional is extremely important when using TD-DFT excitation values for the prediction of the emission energies of iridium and platinum OLED complexes.

Basis Set Dependence. After determining the best functional(s), we examined the basis set dependence of the TD-DFT calculations. The two best functionals, B3LYP and M06, were used to geometry optimize the complexes and calculate the excitation energies using several basis sets, Fig. 3 (see Fig. ESM1 in Supporting Information for complete representation of basis sets). As previously mentioned, the main focus was on the correlation between the experimental $77 \mathrm{~K}$ data and the results from solvated calculations. The relationship between $298 \mathrm{~K}$ and gas phase calculated results is of lesser importance, but may provide insight into the shift of the complexes emission maxima at room temperature. This point will be further investigated in future work.

The top graph in Fig. 3 plots the calculated T1 values versus experimental emission maxima at $77 \mathrm{~K}$ for iridium complexes using different basis sets. Changing the basis set to the LANL2dz had only a small effect on the calculated T1 values for iridium when employing the B3LYP functional. The MADP was reduced to $1.4 \%$ (A, Table 4) from $1.7 \%$ with CEP-31G (Table 2). Using M06/LANL2dz for both optimization and excitation calculations has a MAPD value of $2.6 \%$, which is lower than the original value of $3.1 \%$, but remains less accurate than the results from B3LYP in Table 4. Because of its overall better performance, further basis set changes were only tested with B3LYP.

Analysis of Fig. 3 data shows the best functional/basis set combination for the calculation of the T1 emission is B3LYP/LANL2dz/CEP-31G THF (orange in Fig. 3, method F in Table 4). This method uses B3LYP/LANL2dz for geometry optimization followed by B3LYP/CEP-31G for calculation of excited states using the CPCM solvation model with THF as the solvent. The calculated MAPD with this method is reduced to $1.1 \%$. Furthermore, method $\mathbf{F}$ reduces the number of iridium complexes with a calculated $\Delta_{\mathrm{nm}}$ greater than $10 \mathrm{~nm}$ to two; Ir1 and Ir13, which are calculated to be blue shifted by 10 and $11 \mathrm{~nm}$ respectively.

More interesting are the results calculated for the 20 platinum complexes. Although inherently more challenging to accurately calculate T1 values, Table 3, platinum complexes performed well with changes to the basis set. Similar to iridium, B3LYP, method A, outperforms M06, method B, with calculated MAPDs of $1.5 \%$ and $2.7 \%$, respectively. A more dramatic decrease in the calculated MAPD is seen when method $\mathbf{F}$ is used for platinum. The calculated MAPD is reduced to $0.9 \%$, which is about half the magnitude of the other basis sets and almost 4 times lower than its original value of $3.7 \%$. Only 3 platinum complexes, using method F, have a calculated $\Delta_{\mathrm{nm}}$ greater than $5 \mathrm{~nm}$; Pt4, Pt14, and Pt19, and none of these three are greater than $15 \mathrm{~nm}$.

Table 4. Calculated MAPD values for OLED complexes using various basis sets. Comparison of data is performed with the $77 \mathrm{~K}$ experimental data. ${ }^{a}$

\begin{tabular}{cccc}
\hline & Method & $\begin{array}{c}\text { Iridium } \\
\text { MAPD (77 } \\
\text { K) }\end{array}$ & $\begin{array}{c}\text { Platinum } \\
\text { MAPD (77 K) }\end{array}$ \\
\hline (A) & B3LYP/LANL2dz/THF & 1.4 & 1.5 \\
(B) & M06/LANL2dz/THF & 2.6 & 2.7 \\
(C) & B3LYP/CEP-121G/THF & 1.3 & 2.2 \\
(D) & B3LYP/LANL2dz/CEP- & 1.2 & 0.9 \\
(E) & B3LYP/CEP-31G/LANL2dz_THF & 1.4 & 1.8 \\
(F) & B3LYP/LANL2dz/CEP-31G_THF & 1.1 & 0.9 \\
(G) $^{b}$ & B3LYP/CEP-121G_6- & 4.4 & 4.0 \\
(H) $^{c}$ & 311G(d,p)/THF & & 4.1 \\
(I) $^{d}$ & B3LYP/CEP-31G_6- & 3.9 & 4.0 \\
\hline THF $^{c}$ & B31G(d,p)/THF & & \\
\hline
\end{tabular}

${ }^{a}$ THF written directly after the second forward slash indicates the same basis set was used for optimization and excited state calculations.

${ }^{b}$ Split basis set: CEP-121G on metal, 6-311G(d,p) on all other atoms.

${ }^{c}$ Split basis set: CEP31G on metal, 6-31G(d,p) on all other atoms.

${ }^{d}$ Split basis set: LANL2dz on metal, 6-311G(d,p) on all other atoms.

It is worth noting here that only subtle differences were seen between the CEP-31G and CEP-121G basis sets, methods $\mathbf{F}$ and $\mathbf{D}$. Platinum shows no difference in value while there is a small $0.1 \%$ difference in calculated MAPD, favoring the double zeta, CEP-31G basis set in the case of iridium. Therefore, the computational cost can be reduced by using the smaller basis set without loss of accuracy for iridium and platinum complexes. Comparison of methods $\mathbf{E}$ and $\mathbf{F}$ also show that it is important which basis set is used for the optimization and which basis set is used for the calculation of excitations. Method $\mathbf{E}$ is simply the reverse of method $\mathbf{F}$, however, calculated excitation values of iridium and platinum are more accurate with 
method F. Lastly, calculated MADP values from Table 4 are larger by a factor of about three for iridium and about four for platinum when using split basis sets in methods $\mathbf{G}, \mathbf{H}$ and $\mathbf{I}$.

Solvent Model Dependence. Lastly, selection of the optimal solvent model was investigated by testing three popular solvent models: CPCM (which has been used up to this point), IEFPCM, and SMD. Calculations used method $\mathbf{F}$ from Table 3 to test all iridium and platinum complexes. While the inclusion of solvent is very important for an accurate description of emission energy for comparison against experimental $77 \mathrm{~K}$ data, as previously discussed, the actual solvation model used is not as important.

For iridium, the calculated MAPD values are $1.1 \%, 1.8 \%$, and $1.3 \%$ for CPCM, IEFPCM and SMD, respectively. Concomitantly, the MAPD for platinum complexes are $0.9 \%$ (CPCM), $0.9 \%$ (IEFPCM), and $1.0 \%$ (SMD). Since most of these complexes are neutral, we would not expect a large difference between solvation models. However, complexes Ir11, Ir12, and Ir13 are cationic complexes and therefore may be more dependent on the solvation model selected. The MAPD values for just these three complexes shows that CPCM $(0.5 \%)$ and SMD $(0.5 \%)$ are slightly favored compared to IEFPCM $(0.9 \%)$, which accounts for the smaller MAPD for CPCM and SMD in the iridium group. While the selection of solvation model does not greatly affect the calculated excitation values, the initial employment of the CPCM solvation model is now retrospectively verified by these results.

\section{Conclusions}

In this work we set out to present and justify a reliable TD-DFT excitation based method for the prediction of the triplet emission (T1) energy values for iridium and platinum complexes used in organic light emitting diodes. Accurate prediction of T1 values through a relatively inexpensive computational procedure is key to providing researchers with a starting point towards the development of novel OLED phosphorescent emitters. In order to prove accuracy, robustness, and cost efficiency of a TD-DFT based method, we calculated excitation values of 14 iridium and 20 platinum complexes, previously reported in the literature, that span the entire visible spectrum and consist of different ligand constructs.

As an initial test for accuracy we employed 10 density functionals, B3LYP, CAM-B3LYP, M06, M06L, M06-HF, M06-2X, M11, PBE0, BP86, and $\omega$ B97X-D to test the influence exact exchange, rangeseparated exchange, and dispersion has on calculated TD-DFT excitation values. Results show that B3LYP and M06 outperformed all other functionals within the TD-DFT framework for predicting T1 values. B3LYP and M06 functionals were then used to test the T1 values dependence on the basis set selected Table 4. Calculated MAPD values indicate the best method as method $\mathbf{F}$, where the optimization is performed with B3LYP/LANL2dz followed by a TD-DFT calculation with B3LYP/CEP-31G_THF to obtain triplet excitation energies. The final parameter tested was the choice of solvation model used in the calculations. The inclusion of a solvent model is extremely important for accuracy (see Tables 2 and 3 ). The largest impact the solvation model had on the data was on cationic complexes Ir11, Ir12, and Ir13. In all results, the CPCM model exhibited slight improvements over IEFPCM and SMD.

We have identified a computational method with the ability to quickly and accurately predict triplet emission energies of phosphorescent transition metal complexes used in OLED devices, requiring only ground state singlet optimizations and vertical TD-DFT calculations. While the focus in this manuscript was on the correlation of $77 \mathrm{~K}$ experimental data and the solvated calculations, there is also a nice agreement between $298 \mathrm{~K}$ data and the calculated gas phase results (Tables 2 and 3). This unexpected result will be further explored to determine how well gas phase calculations, based on the identified best method, might be able to predict the room temperature Stokes shift derived from OLED complexes with more flexible ligand types.

Acknowledgements. This work was supported by the Research Council of Norway (Grant No. 231706/F20 and No. 179568/V30) and from the Norwegian supercomputing program NOTUR (Grant No. NN4654K and NN93330K).

Electronic Supplementary Material (ESM) available: Experimentally derived emission maxima and B3LYP/LANL2dz/gas optimized Cartesian coordinates for all complexes.

\section{References}

1. Adachi C, Baldo MA, Thompson ME, Forrest SR (2001) Nearly 100\% internal phosphorescence efficiency in an organic light emitting device. J App Phys 90 (10):5048-5051. doi:10.1063/1.1409582

2. Baldo MA, O’Brien DF, You Y, Shoustikov A, Sibley S, Thompson ME, Forrest SR (1998) Highly efficient phosphorescent emission fromorganic electroluminescent devices. Nature 395:151. doi:10.1038/25954

3. Baldo MA, Lamansky S, Burrows PE, Thompson ME, Forrest SR (1999) Very high-efficiency green organic light-emitting devices based on electrophosphorescence. Appl Phys Lett 75 (1). doi: $10.1063 / 1.124258$

4. Yasukawa N, Ikemizu D, Oshiyama T, Nishizeki M, Tanaka T (2012) Organic Electroluminescent Device, Display Apparatus, and Lighting Apparatus. United States Patent US20120018714A1,

5. Kimyonok A, Domercq B, Haldi A, Cho J-Y, Carlise JR, Wang X-Y, Hayden LE, Jones SC, Barlow S,

Marder SR, Kippelen B, Weck M (2007) Norbornene-Based Copolymers with Iridium Complexes and Bis(carbazolyl)fluorene Groups in Their Side-Chains and Their Use in Light-Emitting Diodes. Chem Mater 19:5602-5608. doi:10.1021/cm0717357

6. Rausch AF, Murphy L, Williams JAG, Yersin H (2012) Improving the Performance of Pt(II) Complexes for Blue Light Emission by Enhancing the Molecular Rigidity. Inorg Chem 51:312-319. doi:10.1021/ic201664v

7. Solomatina AI, Krupenya DV, Gurzhiy VV, Zlatkin I, Pushkarev AP, Bochkarev MN, Besley NA, Bichoutskaia E, Tunik SP (2015) Cyclometallated platinum(II) complexes containing NHC ligands: 
synthesis, characterization, photophysics and their application as emitters in OLEDs. Dalton Trans 44 (16):7152-7162. doi:10.1039/c4dt03106g

8. Shang X, Han D, Zhan Q, Zhang G, Li D (2014) DFT and TD-DFT Study on the Electronic Structures and Phosphorescent Properties of a Series of Heteroleptic Iridium(III) Complexes. Organometallics 33:3300-3308. doi:10.1021/om401194z

9. Xu S, Wang J, Xia H, Zhao F, Wang Y (2015) Computational prediction for emission energy of iridium (III) complexes based on TDDFT calculations using exchange-correlation functionals containing various HF exchange percentages. J Mol Model 21. doi:10.1007/s00894-014-2557-1

10. Tomasi J (2004) Thirty Years of Continuum Solvation Chemistry: A Review and Prospects for the near Future. Theor Chem Acc 112 (4):184-203. doi:10.1007/s00214-004-0582-3

11. Kolosov D, Adamovich V, Djurovich P, Thompson ME, Adachi C (2002) 1,8-Naphthalimides in Phosphorescent Organic LEDs: The Interplay between Dopant, Exciplex, and Host Emission. J Am Chem Soc 124:9945-9954. doi:10.1021/ja0263588

12. Ye S, Liu Y, Di C-a, Xi H, Wu W, Wen Y, Lu K, Du C, Liu Y, Yu G (2009) Wide-Energy-Gap Host Materials for Blue Phosphorescent Organic Light-Emitting Diodes. Chem Mater 21:1333-1342. doi: $10.1021 / \mathrm{cm} 8032302$

13. Niehaus TA, Hofbeck T, Yersin H (2015) Charge-transfer excited states in phosphorescent organotransition metal compounds: a difficult case for time dependent density functional theory? RSC Adv 5:63318-63329. doi:10.1039/c5ra12962a

14. Frisch MJ, Trucks GW, Schlegel HB, Scuseria GE, Robb MA, Cheeseman JR, Scalmani G, Barone V, Mennucci B, Petersson GA, Nakatsuji H, Caricato M, Li X, Hratchian HP, Izmaylov AF, J. Bloino GZ, Sonnenberg JL, Hada M, Ehara M, Toyota K, Fukuda R, Hasegawa J, Ishida M, Nakajima T, Honda Y, Kitao O, Nakai H, Vreven T, J. A. Montgomery J, Peralta JE, Ogliaro F, Bearpark M, Heyd JJ, Brothers E, Kudin KN, Staroverov VN, Keith T, Kobayashi R, Normand J, Raghavachari K, Rendell A, Burant JC, Iyengar SS, Tomasi J, Cossi M, Rega N, Millam JM, Klene M, Knox JE, Cross JB, Bakken V, Adamo C, Jaramillo J, Gomperts R, Stratmann RE, Yazyev O, Austin AJ, Cammi R, Pomelli C, Ochterski JW, Martin RL, Morokuma K, Zakrzewski VG, Voth GA, Salvador P, Dannenberg JJ, Dapprich S, Daniels AD, Farkas O, Foresman JB, Ortiz JV, Cioslowski J, Fox DJ (GAUSSIAN 09 (Revision D.01), Gaussian Inc., Wallingford, CT, 2013).

15. Hohenberg P, Kohn W (1964) Inhomogeneous Electron Gas. Phys Rev 136 (3B):B864-B871. doi:10.1103/PhysRev.136.B864

16. Fermi E (1928) Eine statistische Methode zur Bestimmung einiger Eigenschaften des Atoms und ihre Anwendung auf die Theorie des periodischen Systems der Elemente. Z Phys 48 (144). doi:10.1007/BF01351576

17. Caillie CV, Amos RD (2000) Geometric derivatives of density functional theory excitation energies using gradient-corrected functionals. Chem Phys Lett 317 (1-2). doi:10.1016/S0009-2614(99)01346-9

18. Stratmann RE, Scuseria GE, Frisch MJ (1998) An efficient implementation of time-dependent densityfunctional theory for the calculation of excitation energies of large molecules. J Chem Phys 109 (19). doi: $10.1063 / 1.477483$

19. Scalmani G, Frisch MJ, Mennucci B, Tomasi J, Cammi R, Barone V (2006) Geometries and properties of excited states in the gas phase and in solution: Theory and application of a time-dependent density functional theory polarizable continuum model. J Chem Phys 124:094107-094101-094115. doi: $10.1063 / 1.2173258$

20. Yersin H, Rausch AF, Czerwieniec R, Hofbeck T, Fischer T (2011) The triplet state of organotransition metal compounds. Triplet harvesting and singlet harvesting for efficient OLEDs. Coord Chem Rev 255. doi:10.1016/j.ccr.2011.01.042

21. Yersin H (2008) Highly Efficient OLEDs with Phosphorescent Materials. Wiley-VCH Verlag GmbH \& Co., KGaA, Weinheim. doi:10.1002/9783527621309

22. Becke AD (1993) A new mixing of Hartree-Fock and local density-functional theories. J Chem Phys 98 (2):1372-1377. doi:10.1063/1.464304

23. Adamo C, Barone V (1999) Toward reliable density functional methods without adjustable parameters: The PBE0 model. J Chem Phys 110 (13):6158-6170. doi:10.1063/1.478522

24. Perdew JP, Burke K, Ernzerhof M (1996) Generalized Gradient Approximation Made Simple. Phys Rev Lett 77 (18):3865-3868. doi:10.1103/PhysRevLett.77.3865

25. Jacquemin D, Perpete EA, Ciofini I, Adamo C, Valero R, Zhao Y, Truhlar DG (2010) On the Performances of the M06 Family of Density Functionals for Electronic Excitation Energies. J Chem Theory Comp 6 (7):2071-2085. doi:10.1021/ct100119e

26. Zhao Y, Truhlar DG (2008) Density Functionals with Broad Applicability in Chemistry. Acc Chem Res 41 (2):157-167. doi:10.1021/ar700111a

27. Zhao Y, Truhlar DG (2006) A new local density functional for main-group thermochemistry, transition metal bonding, thermochemical kinetics, and noncovalent interactions. J Chem Phys 125:194101-194101194118. doi:10.1063/1.2370993

28. Zhao Y, Truhlar DG (2008) The M06 suite of density functionals for main group thermochemistry, thermochemical kinetics, noncovalent interactions, excited states, and transition elements: two new functionals and systematic testing of four M06-class functionals and 12 other functionals. Theor Chem Acc 120:215-241. doi:10.1007/s00214-007-0310-x

29. Beck AD (1988) Density-fnnctional exchange-energy approximation with correct asymptotic behavior. Phys Rev A 38 (6):3098-3100. doi:10.1103/PhysRevA.38.3098

30. Perdew JP (1986) Density-functional approximation for the correlation energy of the inhomogeneous electron gas. Phys Rev B 33 (12):8822-8824. doi:10.1103/PhysRevB.33.8822

31. Yanai T, Tew DP, Handy NC (2004) A new hybrid exchange-correlation functional using the Coulomb-attenuating method (CAM-B3LYP). Chem Phys Lett 393:51-57. doi:10.1016/j.cplett.2004.06.011

32. Peverati R, Truhlar DG (2011) Improving the Accuracy of Hybrid Meta-GGA Density Functionals by Range Separation. J Phys Chem Lett 2:2810-2817. doi:10.1021/jz201170d 
33. Chai J-D, Head-Gordon M (2008) Long-range corrected hybrid density functionals with damped atomatom dispersion correctionsw. Phys Chem Chem Phys 10:6615-6620. doi:10.1039/b810189b

34. Stevens WJ, Basch H, Krauss M (1984) Compact effective potentials and efficient shared-exponent basis sets for the first- and second-row atoms. J Chem Phys 81 (12):6026-6033. doi:10.1063/1.447604

35. Hay PJ, Wadt WR (1985) Ab initio effective core potentials for molecular calculations. Potentials for K to Au including the outermost core orbitals. J Phys Chem 82 (1):299-310. doi:10.1063/1.448975

36. Hay PJ, Wadt WR (1985) Ab Initio effective core potentials for molecular calculations. Potentials for the transition metal atoms Sc to Hg. J Phys Chem 82 (1):270-283. doi:10.1063/1.448799

37. Hay PJ, Wadt WR (1985) Ab Initio effective core potentials for molecular calculations. Potentials for main group elements Na to Bi. J Phys Chem 82 (1):284-298. doi:10.1063/1.448800

38. Jr. THD, Hay PJ (1977) Modern Theoretical Chemistry, vol 3. Plenum, New York

39. Francl MM, Pietro WJ, Here WJ, Binkley JS, Gordon MS (1982) Self- consistent molecular orbital methods. XXIII. A polarization- type basis set for second- row elements. J Chem Phys 77 (7):3654-3665. doi:10.1063/1.444267

40. Herre WJ, Ditchfield R, Pople JA (1972) Self-Consistent Molecular Orbital Methods. XII. Further Extensions of Gaussian-Type Basis Sets for Use in Molecular Orbital Studies of Organic Molecules. J Chem Phys 56 (5):2257-2261. doi:10.1063/1.1677527

41. Krishnan R, Binkley JS, Seeger R, Pople JA (1980) Self-consistent molecular orbital methods. XX. A basis set for correlated wave functions. J Chem Phys 72 (1):650-654. doi:10.1063/1.438955

42. McLean AD, Chandler GS (1980) Contracted Gaussian basis sets for molecular calculations. I. Second row atoms, $Z=11-18$. J Chem Phys 72 (10):5639-5648. doi:10.1063/1.438980

43. Cances E, Mennucci B, Tomasi J (1997) A new integral equation formalism for the polarizable continuum model: Theoretical background and applications to isotropic and anisotropic dielectrics. Chem Phys 107 (8):3032-3041. doi:10.1063/1.474659

44. Tomasi J, Mennucci B, Cancès E (1999) The IEF version of the PCM solvation method: an overview of a new method addressed to study molecular solutes at the QM ab initio level. J Mol Struct (Theochem) 464 (1-3):211-226. doi:10.1016/S0166-1280(98)00553-3

45. Marenich AV, Cramer CJ, Truhlar DG (2009) Universal Solvation Model Based on Solute Electron Density and on a Continuum Model of the Solvent Defined by the Bulk Dielectric Constant and Atomic Surface Tensions. J Phys Chem B 113 (18):6378-6396. doi:10.1021/jp810292n

46. Sajoto T, Djurovich PI, Tamayo AB, Oxgaard J, III WAG, Thompson ME (2009) Temperature Dependence of Blue Phosphorescent Cyclometalated Ir(III) Complexes. J Am Chem Soc 131 (28):98139822. doi:10.1021/ja903317w

47. Adachi C, Kwong RC, Djurovich P, Adamovich V, Baldo MA, Thompson ME, Forrest SR (2001) Endothermic energy transfer: A mechanism for generating very efficient high-energy phosphorescent emission in organic materials. App Phys Lett 79 (13):2082-2084. doi:10.1063/1.1400076

48. Chiu Y-C, Chi Y, Hung J-Y, Cheng Y-M, Yu Y-C, Chung M-W, Lee G-H, Chou P-T, Chen C-C, Wu C-C, Hsieh| H-Y (2009) Blue to True-Blue Phosphorescent IrIII Complexes Bearing a Nonconjugated Ancillary Phosphine Chelate: Strategic Synthesis, Photophysics, and Device Integration. App Materials \& Interfaces 1 (2):433-442. doi:10.1021/am800122n

49. Lee SJ, Park K-M, Yang K, Kang Y (2009) Blue Phosphorescent Ir(III) Complex with High Color Purity: fac-Tris(2',6'-difluoro-2,3'-bipyridinato-N,C4')iridium(III). Inorg Chem 48 (3):1030-1037. doi: $10.1021 /$ ic $801643 \mathrm{p}$

50. Tordera D, Serrano-Pérez JJ, Pertegás A, Ortí E, Bolink HJ, Baranoff E, Nazeeruddin MK, Frey J (2013) Correlating the Lifetime and Fluorine Content of Iridium(III) Emitters in Green Light-Emitting Electrochemical Cells. Chem Mater 25:3391-3397. doi:10.1021/cm402473j

51. Li H, Yin Y-M, Cao H-T, Sun H-Z, Wang L, Shan G-G, Zhu D-X, Su Z-M, Xie W-F (2014) Efficient greenish-blue phosphorescent iridium(III) complexes containing carbene and triazole chromophores for organic light-emitting diodes. J Organometallic Chem 753:55-62. doi:10.1016/j.jorganchem.2013.11.036 52. Brooks J, Babayan Y, Lamansky S, Djurovich PI, Tsyba I, Bau R, Thompson ME (2002) Synthesis and Characterization of Phosphorescent Cyclometalated Platinum Complexes. Inorg Chem 41 (12):3055-3066 53. Ravindranathan D, Vezzu DAK, Bartolotti L, Boyle PD, Huo S (2010) Improvement in Phosphorescence Efficiency through Tuning of Coordination Geometry of Tridentate Cyclometalated Platinum(II) Complexes. Inorg Chem 49 (19):8922-8928. doi:10.1021/ic101109h

54. Vezzu DAK, Ravindranathan D, Garner AW, Bartolotti L, Smith ME, Boyle PD, Huo S (2011) Highly Luminescent Tridentate $\mathrm{N} \wedge \mathrm{C} * \mathrm{~N}$ Platinum(II) Complexes Featured in Fused Five-Six-Membered Metallacycle and Diminishing Concentration Quenching. Inorg Chem 50:8261-8273. doi:10.1021/ic200794b

55. Fleetham T, Li G, Wen L, Li J (2014) Effi cient "Pure" Blue OLEDs Employing Tetradentate Pt Complexes with a Narrow Spectral Bandwidth. Adv Mater 26:7116-7121. doi:10.1002/adma.201401759 56. Hudson ZM, Sun C, Helander MG, Amarne H, Lu Z-H, Wang S (2010) Enhancing Phosphorescence and Electrophosphorescence Effi ciency of Cyclometalated Pt(II) Compounds with Triarylboron. Adv Funct Mater 20:3426-3439. doi:10.1002/adfm.201000904 